\title{
Unsheltered homeless and unstably housed adults have higher levels of stress and more health risk factors than sheltered homeless adults
}

Chaelin K. Ra ( $\sim$ chaelin-ra@ouhsc.edu )

University of Oklahoma Health Sciences Center https://orcid.org/0000-0002-7379-7247

Emily T. Hébert

University of Oklahoma Health Sciences Center

Adam Alexander

University of Oklahoma Health Sciences Center

Darla E. Kendzor

University of Oklahoma Health Sciences Center

Robert Suchting

University of Texas Health Science Center at Houston

Michael S. Businelle

University of Oklahoma Health Sciences Center

\section{Research}

Keywords: homeless, housing, health

Posted Date: November 23rd, 2020

DOI: https://doi.org/10.21203/rs.3.rs-113002/v1

License: @ (1) This work is licensed under a Creative Commons Attribution 4.0 International License. Read Full License 


\section{Abstract}

Background: In the United States, approximately 568,000 individuals are homeless on a single night. Homelessness can be categorized into three subgroups: sheltered homeless, unsheltered homeless, and unstably housed. Few studies have examined the relations between homelessness subtypes, shelter service utilization, levels of stress experienced, and health risk factors. This study aimed to empirically examine whether shelter status the previous night was related to current stress, recent utilization of shelter-based mental health services, and current health risk factors.

Methods: Data were collected at multiple homeless shelters in 2016 in the Oklahoma City area $(\mathrm{N}=575)$. All participants completed assessments of demographic characteristics, including age, sex, race, marital status, years of education, and incarceration history and victimization. Multiple linear and logistic regression analyses were conducted to examine relations between homelessness subgroups and outcomes (shelter-based service utilization, health risk factors, and stressors).

Results: Results indicated that the sheltered group was younger and more likely to be White than the unsheltered group, had higher levels of education, and reported more lifetime months in jail than the unstably housed group. In addition, unsheltered homeless and unstably housed adults used fewer shelter-based health services, exhibited more health risk factors, experienced greater levels of stress, and had higher levels of food insecurity than sheltered homeless adults.

Conclusion: Homeless adults who reside at shelters benefit most from available shelter services. The development of policies and programs targeted toward increasing sheltering options for unsheltered and unstably housed adults is needed.

\section{Background}

People experiencing homelessness are among the most vulnerable members of society, and homelessness comes with important health implications. In January 2019, the number of people experiencing homelessness on a single night was estimated to be 568,000 in the United States (1). Nearly two-thirds (63\%) were located in emergency shelters and transitional housing programs, and more than one-third (37\%) slept on the streets, or in places not intended for human habitation, such as sidewalks, parks, cars, or abandoned buildings (1).

Previous studies have found that, compared with domiciled adults, people experiencing homelessness are more likely to experience chronic stress, food insecurity, sleep problems, mental health disorders, alcoholism, substance abuse, and injuries (2-7). For instance, $43 \%$ of adults experiencing homelessness in the U.S. reported having a substance abuse disorder or other mental health problems, and an additional $23 \%$ reported both (8). Homeless adults face significant barriers that limit their access to health care, which leads to increased health care costs and poorer health outcomes (3). In fact, more than half of adults experiencing homelessness do not have health insurance in the United States (9).

Homeless populations can be categorized into three subgroups based on where they reside: 1) individuals residing in an emergency shelter, transitional housing, or supportive housing, termed "sheltered homeless" in this study, 2) individuals residing in a location not meant for human habitation such as a car, park, sidewalk, abandoned building (on the street) termed "unsheltered homeless" in this study, and 3) individuals who sleep overnight with family, friends, acquaintances, sex partners or hotel/motel termed "unstably housed" in this study $(3,10)$. This definition was based on the U.S. Department of Housing and Urban Development's point-in-time method for counting sheltered homeless persons, which is utilized to avoid duplicate estimates of homeless persons in sheltered and unsheltered locations (23).

Few studies have examined the relations among the aforementioned homelessness subtypes, shelter service utilization, and health behaviors. One study found that unsheltered women experiencing homelessness were more likely to use alcohol and drugs than domiciled women, had a higher risk of both poor mental and physical health, and were less likely to utilize available health services, including drug and alcohol abuse treatments (11). Another study compared unsheltered and sheltered homeless adults in terms of their demographics and health service use. Findings indicated that unsheltered participants were less likely to have insurance and more likely to use emergency services and outpatient services than sheltered participants (12). Previous studies focused on this topic have had limitations. For instance, previous studies have focused on specific populations (e.g., unsheltered homeless only (13), Mexican girls (14), women (11), or veterans (15)), did not include unstably housed people, or did not examine health behaviors or 
health service utilization. Further examination of these topics is needed to identify better ways to address health risk factors and improve health in this population.

Previous research has indicated that shelters which provide services to homeless adults can improve health outcomes, including reducing mental health problems, increasing health care use, reducing substance abuse, reducing daily stress, and improving healthy behaviors $(16,17)$. However, some shelters have rules about who can stay there based on sex, arrest history, sexual violence, etc (18). Thus, unsheltered homeless and unstably housed people who are not allowed to stay at shelters may have worse outcomes compared with sheltered homeless adults. Specifically, they may be less likely to utilize health care services, and this may have detrimental effects on their health behaviors and health outcomes (19). Understanding characteristics of subgroups of homeless adults (sheltered vs. unsheltered vs. unstably housed) could inform health promotion and health intervention programs for this understudied and underserved population. To do so, this study focused on risk and/or protective factors that have an impact on modifiable health behavior changes (i.e., current stress, recent utilization of shelter-based mental health services, and current health risk factors), which are thus targetable for intervention.

The purpose of this study is to empirically examine whether shelter status the previous night was related to current stress, recent utilization of shelter-based mental health services, and current health risk factors provide services to homeless adults can improve health outcomes, including reducing mental health problems, increasing health care use, reducing substance abuse, reducing daily stress, and improving healthy behaviors $(16,17)$.

It is hypothesized that: unsheltered homeless and unstably housed adults will exhibit lower use of shelter-based mental health services, higher levels of stress, and more health risk factors than sheltered homeless adults.

\section{Methods}

\section{Participants and Procedure}

Data were collected at six homeless shelters between July and August 2016 in the Oklahoma City area. Homeless individuals were eligible to participate in this study if they met the following criteria: 1) earned a score $\geq 4$ on the Rapid Estimate of Adult Literacy in Medicine-Short Form (REALM-SF(20)) indicating > 6th grade English literacy level, 2) were $\geq 18$ years of age, and 3) were receiving services at the targeted shelters.

Flyers advertising for this study and sign-up times were posted around shelter campuses. Individuals who were interested in the study were given a screening appointment, and they received detailed information about the study during that appointment. Those who remained interested in participating were screened for study inclusion. Those who qualified for the study completed a tablet-based 1.5-hour survey. Participants who completed the assessments received a $\$ 20$ gift card as compensation. The study procedure was approved by the Institutional Review Board at the University of Oklahoma Health Sciences Center. Details of the study design are described elsewhere.(21-23)

\section{Measures}

Demographics. All participants completed assessments of demographic characteristics, including age, sex, race, marital status, and years of education.

Three homelessness subgroups. Participants were asked, "Where did you sleep last night?" Based on their response, participants were divided into three categories: $(3,24) 1$ ) sheltered homeless (homeless shelter and/or drug or alcohol treatment center), 2) unsheltered homeless (outside or on the street), and 3) unstably housed (friend's or family member's house or apartment, hotel or motel, other temporary location).

Incarceration history and victimization. Incarceration history was assessed using two items, "Have you been incarcerated (jail or prison) in the past year?", and response options were yes (1) or no (0). Participants were also asked, "During your lifetime, how much time have you spent in jail or prison?", and the responses were calculated in months.

Shelter-based service utilization. Shelter-based utilization of mental health services was assessed via four questions, "Over the past 3 months, have you received Mental Health/Behavioral Health Counseling at local shelters?", "Over the past 3 months, have you 
received Substance Abuse Counseling at local shelters?", "Over the past 3 months, have you received any meals at local shelters?", and "Over the past 3 months, have you met a case manager at local shelters?", and response options were yes (1) or no (0).

Health risk factors. Physical activity in the past week, sleep, binge drinking in the past month, drug use yesterday, and obesity were assessed. Physical activity was assessed using two items to determine whether, in a usual week, participants participated in moderate-intensity physical activities such as brisk walking, bicycling, vacuuming, or gardening, and/or vigorous-intensity physical activities such as running, aerobics, or heavy yard work. Respondents who indicated that they did moderate- or vigorous-intensity physical activity were also asked to report how many days per week they spent at least 10 minutes at a time doing the activities, and how much total time (in minutes) per day they spent doing the activities. After vigorous minutes were multiplied by 2 , total physical activity minutes were multiplied by the number of days per week to refer to participants' total minutes spent in moderate-to-vigorous physical activity (MVPA) in the past week (25). Sleep deprivation was measured by the responses (yes or no) to the question, "I do not get enough sleep." Binge drinking status was assessed by asking a question, "How often in the past 30 days have you consumed [5 for men/ 4 for women] or more standard drinks?(26)" The responses were dichotomized as "binge drinking in the past 30 days" vs. "no binge drinking in the past 30 days." Drug use was assessed by asking one question, "Please select all the substances that you used yesterday (check all that apply)." Answers were dichotomized into any drug use yesterday (e.g., Cannabis, Cocaine, K2, and Amphetamine) and no drug use yesterday. BMI was calculated based on weight and height, and participants were categorized into underweight or normal (0), and overweight or obese (1) (27).

Stressors. Level of life stress was assessed using the Urban Life Stress Scale, which is a 21-item self-report checklist of potential sources of chronic stress (28). The degree of stress experienced related to each item was rated on a 5-point scale, from 1, "no stress at all," to 5 "extremely stressful - more than I can handle." The USDA Food Security Survey (29) was used to measure food insecurity during the last 12 months. This measure consists of 5 items (e.g., in the last 12 months, you could not afford to eat balanced meals) scored from 0 to 6 .

\section{Statistical Analyses}

Comparisons between three homeless subgroups (i.e., sheltered homeless vs. unsheltered homeless vs. unstably housed) were made using Chi-square tests for categorical variables (e.g., race) or one way ANOVA for continuous variables (e.g., age) with Fisher's Least Significant Difference post-hoc test, as appropriate. The main predictor was the category of three homeless subgroups, and outcomes were shelter-based service utilization, stress measures, and the presence of specific health risk factors. Multiple linear regression was used to examine the relations between homeless subgroups and continuous outcomes (e.g., the Urban Life Stress Scale), and logistic regression was used for binary outcomes (e.g., binge drinking last month: yes or no) adjusting for covariates (i.e., age, sex, years of education, and race). All analyses were performed using SPSS version 25.

\section{Results}

\section{Sample Description}

Table 1 presents frequencies and percentages for all variables and differences between the three homelessness subgroups. 
Table 1

Sample characteristics by sheltering type.

\begin{tabular}{|c|c|c|c|c|}
\hline \multirow[t]{2}{*}{ Characteristics } & \multirow{2}{*}{$\begin{array}{l}\text { Total }(N= \\
575)\end{array}$} & \multicolumn{3}{|c|}{ States of homelessness, $\mathbf{N}(\%)$} \\
\hline & & $\begin{array}{l}\text { Sheltered homeless }(n= \\
\text { 401) }\end{array}$ & $\begin{array}{l}\text { Unsheltered homeless }(n= \\
\text { 119) }\end{array}$ & $\begin{array}{l}\text { Unstably housed }(n= \\
55)\end{array}$ \\
\hline \multicolumn{5}{|l|}{$\begin{array}{l}\text { Sociodemographic } \\
\text { Characteristics }\end{array}$} \\
\hline Age, M (SD) & $\begin{array}{l}43.65 \\
(12.16)\end{array}$ & $42.64(12.76)^{a}$ & $47.42(9.68)^{b}$ & $42.82(11.14)^{a, b}$ \\
\hline $\begin{array}{l}\text { Years of education, } \\
M(S D)\end{array}$ & $11.94(2.04)$ & $12.07(2.06)^{a}$ & $11.81(1.97)^{\mathrm{a}, \mathrm{b}}$ & $11.31(1.95)^{\mathrm{b}}$ \\
\hline \multicolumn{5}{|l|}{ Sex } \\
\hline Male & $366(63.7)$ & $248(61.8)$ & $87(73.1)$ & $31(56.4)$ \\
\hline Female & $209(36.3)$ & $153(38.2)$ & $32(26.9)$ & $24(43.6)$ \\
\hline \multicolumn{5}{|l|}{ Race } \\
\hline White & $324(56.3)$ & $244(60.8)^{a}$ & $52(43.7)^{\mathrm{b}}$ & $28(50.9)^{a, b}$ \\
\hline Other ${ }^{*}$ & $251(43.7)$ & $157(39.2)^{\mathrm{a}}$ & $67(56.3)^{\mathrm{b}}$ & $27(49.1)^{a, b}$ \\
\hline \multicolumn{5}{|l|}{ Incarceration History } \\
\hline $\begin{array}{l}\text { Months in jail lifetime, M } \\
\text { (SD) }\end{array}$ & $\begin{array}{l}32.73 \\
(60.41)\end{array}$ & $24.56(50.54)^{a}$ & $49.32(65.78)^{b}$ & $56.68(93.51)^{b}$ \\
\hline Incarcerated in jail last year & $212(36.9)$ & $145(36.2)^{a, b}$ & $54(45.8)^{a}$ & $13(23.6)^{b}$ \\
\hline
\end{tabular}

Sociodemographic characteristics. Analyses indicated that the sheltered group was younger and more likely to be Whitethan the unsheltered group ( 42.64 vs. $47.42 ; 60.8 \%$ vs. $50.9 \%$, respectively). In addition, sheltered homeless had higher levels of education than the unstably housed group (12.07 vs. 11.31) (see Table 1).

Incarceration history. Results indicated that unsheltered homeless and unstably housed groups reported more lifetime months in jail compared with the sheltered homeless group (49.32 and 56.68 vs. 24.56). Also, unsheltered homeless were more likely to report incarceration in the past year compared with unstably housed individuals (45.8\% vs. $23.6 \%$ ) (see Table 1 ).

\section{Comparison of Use of Shelter-based Healthcare Services, Health Risk Factors, and Stressors as a Function of State of Homelessness}

Shelter-based service utilization. A higher proportion of sheltered homeless reported receiving mental health/behavioral health counseling ( $30.7 \%$ vs. $15.3 \%$ and $9.1 \%$, respectively), substance abuse counseling ( $27.2 \%$ vs. $5.1 \%$ and $5.5 \%$, respectively), and meeting a case manager in the past 90 days ( $78.6 \%$ vs. $39.0 \%$ and $36.4 \%$, respectively) than unsheltered homeless and unstably housed adults (see Table 2). The proportion who received meals at shelters was not different $(p<.05)$ between the three subgroups (see Table 2). Similar results were found after controlling for covariates (see Table 2). 
Table 2

Comparison of shelter-based healthcare service utilization, health risk factors, and stressors as a function of sheltering type.

\begin{tabular}{|c|c|c|c|c|c|c|c|c|c|}
\hline \multirow{3}{*}{$\begin{array}{l}\text { Outcomes } \\
\text { Sheltered } \\
\text { homeless ( } \mathrm{n}= \\
401)\end{array}$} & \multicolumn{4}{|l|}{ Unadjusted } & \multicolumn{5}{|c|}{ Adjusted } \\
\hline & \multirow{2}{*}{$\begin{array}{l}\text { Total }(\mathbf{N}= \\
575) \\
\text { Unsheltered } \\
\text { homeless } \\
(\mathbf{n}=119)\end{array}$} & \multicolumn{3}{|c|}{ States of homelessness, N (\%) } & \multirow{2}{*}{$\begin{array}{l}\begin{array}{l}\text { Sheltered } \\
\text { homeless }\end{array} \\
\text { P-value }\end{array}$} & \multicolumn{2}{|c|}{$\begin{array}{l}\text { Unsheltered } \\
\text { homeless }\end{array}$} & \multicolumn{2}{|c|}{ Unstably housed } \\
\hline & & $\begin{array}{l}\text { Unstably } \mathrm{h} \\
\text { 55) }\end{array}$ & oused $(n=$ & $\begin{array}{l}\text { B } \\
\text { (SE) }\end{array}$ & & $\mathrm{B}$ (SE) & $\begin{array}{l}\text { P- } \\
\text { value }\end{array}$ & & \\
\hline \multicolumn{10}{|l|}{$\begin{array}{l}\text { Shelter-based } \\
\text { health service }\end{array}$} \\
\hline $\begin{array}{l}\text { Mental } \\
\text { health/Behavioral } \\
\text { health }\end{array}$ & $146(25.4)$ & $\begin{array}{l}123 \\
(30.7)^{a}\end{array}$ & $18(15.3)^{b}$ & $5(9.1)^{b}$ & - & $\begin{array}{l}-0.77 \\
(0.29)\end{array}$ & 0.007 & $\begin{array}{l}-1.46 \\
(0.49)\end{array}$ & 0.003 \\
\hline \multicolumn{10}{|l|}{ counseling } \\
\hline $\begin{array}{l}\text { Substance abuse } \\
\text { counseling }\end{array}$ & $118(20.6)$ & $\begin{array}{l}109 \\
(27.2)^{a}\end{array}$ & $6(5.1)^{b}$ & $3(5.5)^{b}$ & - & $\begin{array}{l}-1.82 \\
(0.44)\end{array}$ & $<.001$ & $\begin{array}{l}-1.74 \\
(0.61)\end{array}$ & 0.004 \\
\hline Receiving meals & $535(93.2)$ & $\begin{array}{l}379 \\
(94.5)\end{array}$ & $108(91.5)$ & $48(87.3)$ & & $\begin{array}{l}-0.65 \\
(0.42)\end{array}$ & 0.12 & $\begin{array}{l}-0.84 \\
(0.47)\end{array}$ & 0.08 \\
\hline $\begin{array}{l}\text { Meeting a case } \\
\text { manager }\end{array}$ & $381(66.4)$ & $\begin{array}{l}315 \\
(78.6)^{a}\end{array}$ & $46(39.0)^{b}$ & $20(36.4)^{b}$ & & $\begin{array}{l}-1.67 \\
(0.23)\end{array}$ & $<.001$ & $\begin{array}{l}-1.88 \\
(0.31)\end{array}$ & $<.001$ \\
\hline \multicolumn{10}{|l|}{$\begin{array}{l}\text { Health risk } \\
\text { factors }\end{array}$} \\
\hline $\begin{array}{l}\text { Total minutes of } \\
\text { MVPA (M/SD) }\end{array}$ & $\begin{array}{l}392.14 \\
(755.79)\end{array}$ & $\begin{array}{l}337.45 \\
(627.41)^{a}\end{array}$ & $\begin{array}{l}595.64 \\
(1027.95)^{b}\end{array}$ & $\begin{array}{l}360.72 \\
(863.40)^{a, b}\end{array}$ & - & $\begin{array}{l}261.57 \\
(80.92)\end{array}$ & 0.001 & $\begin{array}{l}36.25 \\
(108.63)\end{array}$ & 0.74 \\
\hline Not enough sleep & $267(46.5)$ & $\begin{array}{l}161 \\
(40.1)^{a}\end{array}$ & $71(60.2)^{b}$ & $35(63.6)^{b}$ & - & $\begin{array}{l}0.88 \\
(0.22)\end{array}$ & $<.001$ & $\begin{array}{l}1.01 \\
(0.30)\end{array}$ & 0.001 \\
\hline $\begin{array}{l}\text { Binge drinking } \\
\text { last month }\end{array}$ & $182(31.8)$ & $\begin{array}{l}83 \\
(20.8)^{a}\end{array}$ & $77(65.8)^{b}$ & $22(40)^{c}$ & - & $\begin{array}{l}1.86 \\
(0.24)\end{array}$ & 0.002 & $\begin{array}{l}0.87 \\
(0.31)\end{array}$ & 0.006 \\
\hline $\begin{array}{l}\text { Drug use } \\
\text { yesterday }\end{array}$ & $73(12.7)$ & $19(4.7)^{\mathrm{a}}$ & $35(29.4)^{b}$ & $19(34.5)^{b}$ & & $\begin{array}{l}2.16 \\
(0.32)\end{array}$ & $<.001$ & $\begin{array}{l}2.39 \\
(0.38)\end{array}$ & $<.001$ \\
\hline $\begin{array}{l}\text { Overweight or } \\
\text { obese }\end{array}$ & 366 (63.7) & $\begin{array}{l}275 \\
(68.6)^{a}\end{array}$ & $60(50.4)^{b}$ & $31(56.4)^{a, b}$ & & $\begin{array}{l}-0.82 \\
(0.22)\end{array}$ & $<.001$ & $\begin{array}{l}-0.50 \\
(0.30)\end{array}$ & 0.09 \\
\hline \multicolumn{10}{|l|}{ Stressors } \\
\hline $\begin{array}{l}\text { Daily Stress }{ }^{3} \\
(\mathrm{M} / \mathrm{SD})\end{array}$ & $\begin{array}{l}48.92 \\
(14.96)\end{array}$ & $\begin{array}{l}47.93 \\
(14.89)^{a}\end{array}$ & $\begin{array}{l}51.63 \\
(15.62)^{b}\end{array}$ & $\begin{array}{l}50.31 \\
(13.46)^{a, b}\end{array}$ & - & $\begin{array}{l}4.18 \\
(1.59)\end{array}$ & 0.009 & $\begin{array}{l}2.96 \\
(2.14)\end{array}$ & 0.17 \\
\hline $\begin{array}{l}\text { Food insecurity } 4 \\
\text { (M/SD) }\end{array}$ & 3.82 (2.29) & $\begin{array}{l}3.54 \\
(2.36)^{a}\end{array}$ & $\begin{array}{l}4.59 \\
(1.99)^{b}\end{array}$ & $\begin{array}{l}4.16 \\
(2.03)^{a, b}\end{array}$ & - & $\begin{array}{l}1.14 \\
(0.24)\end{array}$ & $<.001$ & $\begin{array}{l}0.75 \\
(0.33)\end{array}$ & 0.02 \\
\hline \multicolumn{10}{|c|}{$\begin{array}{l}\text { Note. } \mathrm{N}=\text { Sample size, } \mathrm{M}=\text { Mean, } \mathrm{SD}=\text { Standard Deviation, Data displayed in the unadjusted column are based on } 570 \text { to } 575 \\
\text { subjects, depending on the variable, due to missing data, B = Beta, SE = Standard Error, }{ }^{1} \text { Chi-square tests for categorical variables } \\
\text { (sex, race, and incarcerated in jail in the past year) or one way ANOVA for continuous variables (age, years of education, and } \\
\text { months in jail lifetime) with Fisher's Least Significant Difference post-hoc test, Means with differing subscripts are significantly } \\
\text { different at the } p<.05 \text { level. }{ }^{2} \text { All models adjusted for age, years of education, sex, and race. }{ }^{3} \text { The level of life stress was } \\
\text { assessed through the Urban Life Stress Scale, which is a } 21 \text {-item self-report checklist of potential sources of chronic stress. }{ }^{4} \text { The } \\
\text { USDA Food Security Survey was used to measure participants' food insecurity during the last } 12 \text { months. }\end{array}$} \\
\hline
\end{tabular}

Health risk factors. Sheltered adults reported lower total minutes of MVPA per week than unsheltered adults (337.45 vs. 595.64). Binge drinking was highest in the unsheltered group, followed by unstably housed and sheltered homeless (20.8\% vs. $65.8 \%$ vs. $40.0 \%$, respectively). A smaller proportion of sheltered adults reported using any drugs yesterday compared with unsheltered adults 
and unstably housed adults ( $4.7 \%$ vs. $29.4 \%$ and $34.5 \%$, respectively). The proportion that reported they do not get enough sleep was lower among sheltered adults compared with unsheltered and unstably housed adults ( $30.7 \%$ vs. $15.3 \%$ and $9.1 \%$, respectively). A greater proportion of sheltered homeless adults was overweight or obese than unsheltered homeless (68.6\% vs. $50.4 \%)$.Similar results were found after controlling for covariates (see Table 2).

Stressors. Daily stress, as measured by the Urban Life Stress Scale, and food insecurity were lower for sheltered homeless compared with unsheltered homeless (47.93 vs. $51.63 ; 3.54$ vs. 4.59 , respectively). After controlling for covariates, results indicated that unsheltered homeless adults reported higher levels of daily life stress than sheltered homeless adults $(b=4.18, p=0.009)$ and both unsheltered adults and unstably housed adults were more likely than sheltered adults to report food insecurity $(b=1.14, p<0.001 ; b=$ $0.75, p=0.020$, respectively).

\section{Discussion}

The primary purpose of this study was to examine whether shelter status the previous night was related to measures of stress, recent utilization of shelter-based services, and current health risk factors. Consistent with our hypotheses, sheltered homeless adults used more shelter-based mental health services, had fewer health risk factors, and reported lower levels of stress than unsheltered homeless adults and unstably housed adults. That is, unsheltered homeless adults were more likely to report not getting enough sleep, binge drinking, using illicit drugs, and experiencing higher levels of daily stress and food insecurity than sheltered homeless adults. Similarly, unstably housed adults were more likely to report inadequate levels of sleep, binge drink, use illicit drugs, and experience a higher level of food insecurity than sheltered homeless adults.

Our findings are consistent with previous research, indicating that homeless adults who receive shelter-based mental health services may demonstrate better mental health, fewer substance abuse problems, and healthier behaviors $(16,17)$. Sheltered homeless adults may have more access to health care services, and in turn, demonstrate fewer health risk factors and lower levels of stress than unsheltered or unstably housed adults.

To our knowledge, this study is the first to examine levels of physical activity and rates of overweight/obesity among the three homeless subgroups. It is known that insufficient physical activity is common in homeless populations in general (30). Moreover, it has been reported that the rates of overweight and obesity among homeless adults are high and increasing $(4,30,31)$. The findings from the current study indicated that sheltered homeless adults are more likely to be sedentary and overweight or obese than unsheltered homeless adults. However, higher physical activity and lower overweight/obesity rates for unsheltered homeless and unstably housed adults do not necessarily mean that they are healthier than sheltered homeless adults. It may be the case that sheltered homeless adults are more likely to have physical disabilities limiting physical activity, resulting in lower levels of exercise and higher rates of overweight/obesity. Further, unsheltered homeless adults may have lower rates of overweight/obesity and greater levels of physical activity because they eat fewer meals and have to travel from place to place to get their basic needs met (e.g., traveling to various shelters to acquire food). Although there is an increasing number of studies that focus on physical activity and obesity among sheltered homeless adults (30-33), we found none that have similarly targeted unsheltered and unstably housing adults. Interventions that target physical activity and overweight/obesity among unsheltered homeless adults are needed.

Findings from this study also indicate that the heterogeneity of this population should be considered when developing policies and intervention tools to address the health care needs of adults experiencing homelessness. Unsheltered homeless and unstably housed adults appeared to have greater need than sheltered homeless adults, yet they received fewer services at shelters. This finding is consistent with previous research indicating that unsheltered homeless adults have greater needs for care and experience longer periods of lifetime homelessness (11). Furthermore, current study findings showed that unsheltered homeless and unstably housed adults reported longer periods of lifetime incarceration than sheltered homeless adults, and unsheltered homeless adults were more likely to report incarceration in the past year than unstably housed adults. This finding is important because many shelters have rules about who can stay there based on sex, arrest history, sexual violence, etc (18). Thus, many unsheltered homeless or unstably housed adults may not have access to the drop-in services that are available to shelter residents due to their incarceration history (11). Barriers that reduce access to care for unsheltered homeless and unstably housed groups should be considered when developing and implementing policies and intervention tools for this marginalized and underserved population.

This study has several limitations. First, we did not assess duration of sheltered status. The three homeless subgroups (sheltered homeless, unsheltered homeless, and unstably housed) were categorized based on participants' whereabouts the previous night. This 
definition was based on the U.S. Department of Housing and Urban Development's point-in-time method for counting sheltered homeless persons, which is utilized to avoid duplicated estimates of homeless persons in sheltered and unsheltered locations (23). Future longitudinal research should measure the duration of current sheltering status to examine how the duration of sheltered status (e.g., number of nights at the shelter in the previous month) relates to the utilization of shelter-based mental health services, stress, health risk factors, and continued homelessness. Second, unsheltered homeless and unstably housed subgroups may have been underrepresented in this study because the study data were only collected at shelters. Third, the data were collected from adults who homelessness in one city, and the findings may not be generalizable to homeless populations in other U.S. cities, or states. However, this study surveyed a large sample of adults experiencing homelessness, representing a range of races as well as other demographic characteristics from an understudied region of the U.S. When this study was conducted in 2016, there were 1,368 homeless people on a single night in Oklahoma City, meaning that roughly $42 \%$ of this population were included in the study sample (34). Other study limitations include cross-sectional data collection and health service use, health behaviors, and stressors were self-reported. Thus, participants may have under- or over- reported information, and this may have biased the study findings.

\section{Conclusions}

Despite these limitations, findings from this study have notable implications for health research in this understudied population. To best of our knowledge, this is one of the first studies to compare how these homeless subgroups based on where they reside previous night vary in terms of health risk factors, current stress, and shelter-based health service use. Our findings are important as they indicate that unsheltered homeless and unstably housed subpopulations may be more vulnerable and experience greater needs than sheltered homeless adults. Specifically, unsheltered homeless and unstably housed adults are more likely to exhibit lower use of shelter-based health services, higher levels of stress, and more health risk factors than sheltered homeless adults. Homeless shelters play an important role in providing for the basic needs and improving the health of adults experiencing homelessness. Findings from the current study may inform the development of policies and programs that are targeted toward homelessness subgroups.

Additional research is needed to identify barriers to shelter utilization for unstably housed and unsheltered adults experiencing homelessness to inform health promotion and health intervention programs for this understudied and underserved population. Addressing these barriers may improve the health of homeless adults, reduce the duration of homeless bouts, and may ultimately reduce overall homelessness in the U.S.

\section{Declarations}

\section{Ethics approval and consent to participate}

Participants read and signed the informed consent document to participate in research. The study procedure was approved by the Institutional Review Board at the University of Oklahoma Health Sciences Center.

\section{Consent for publication}

Not applicable

\section{Availability of data and materials}

Data and materials are not available to public yet.

\section{Competing interests}

All authors declare that they have no competing interests.

\section{Funding}

This study was supported by the Stephenson Cancer Center via an NCl Cancer Center Support Grant (P30CA225520) and through the Oklahoma Tobacco Settlement Endowment Trust grant 092-016-0002). Data analysis and manuscript preparation were additionally supported through K99DA046564. The contents of the manuscript are solely the responsibility of the authors and do not necessarily represent the official views of the sponsoring organizations. 
Authors' contributions

CKR had full access to all of the study data. MSB and CKR are responsible for the integrity of the data and the accuracy of the data analysis.

Concept and design: CKR, ETH, and MSB

Acquisition, analysis, or interpretation of data: CKR, ETH, RS, and MSB

Drafting the manuscript: CKR, ETH, AA, DEK, and MSB

Critical revision of the manuscript for important intellectual content: CKR, ETH, AA, DEK, RS, and MSB

Statistical Analysis: CKR, ETH, and MSB

\section{Acknowledgements}

We would like to thank the study participants for their time and effort.

\section{References}

1. Meghan Henry RW, Anna Mahathey, Jillian Ouellette, and Aubrey Sitler, Abt Associates. The 2019 annual homeless assessment report (AHAR) to Congress. . MA, USA.: The US Department of Housing and Urban Development, Office of Community Planning and Development; 2020.

2. Bakker EJ, Ravensbergen NJC, Poldermans D. Perioperative cardiac evaluation, monitoring, and risk reduction strategies in noncardiac surgery patients. Current Opinion in Critical Care. 2011;17(5):409-15.

3. Midboe AM, Byrne T, Smelson D, Jasuja G, Mclnnes K, Troszak LK. The Opioid Epidemic In Veterans Who Were Homeless Or Unstably Housed. Health Affairs. 2019;38(8):1289-97.

4. Tsai J, Rosenheck RA. Risk factors for ED use among homeless veterans. The American journal of emergency medicine. 2013;31(5):855-8.

5. Abdelrahman M, Burritt DJ, Tran LSP. The use of metabolomic quantitative trait locus mapping and osmotic adjustment traits for the improvement of crop yields under environmental stresses. Semin Cell Dev Biol. 2018;83:86-94.

6. D'Amore J, Hung O, Chiang W, Goldfrank L. The epidemiology of the homeless population and its impact on an urban emergency department. Academic Emergency Medicine. 2001;8(11):1051-5.

7. Raven MC, Tieu L, Lee CT, Ponath C, Guzman D, Kushel M. Emergency department use in a cohort of older homeless adults: results from the HOPE HOME study. Academic emergency medicine. 2017;24(1):63-74.

8. Hwang SW, Tolomiczenko G, Kouyoumdjian FG, Garner RE. Interventions to improve the health of the homeless: a systematic review. American journal of preventive medicine. 2005;29(4):311-. e75.

9. Kushel MB, Vittinghoff E, Haas JS. Factors associated with the health care utilization of homeless persons. Jama. $2001 ; 285(2): 200-6$.

10. Buron L, McCall T, Solari C. The 2015 Annual Homeless Assessment Report (AHAR) to Congress, Part 2: Estimates of homelessness in the United States, data collection and analysis methodology. Washington, DC: US Department of Housing and Urban Development, Office of ...; 2016.

11. Nyamathi AM, Leake B, Gelberg L. Sheltered versus nonsheltered homeless women. Journal of general internal medicine. 2000;15(8):565-72.

12. Petrovich JC, Hunt JJ, North CS, Pollio DE, Murphy ER. Comparing Unsheltered and Sheltered Homeless: Demographics, Health Services Use and Predictors of Health Services Use. Community mental health journal. 2020;56(2):271-9.

13. Roundtree J, Hess N, Lyke A. Health Conditions Among Unsheltered Adults in the US. 2019.

14. Castaños-Cervantes S, Turnbull B, Aguilar-Villalobos J. Psychosocial differences between Mexican girls at risk of homelessness and those unsheltered, sheltered or emergency sheltered. Vulnerable Children and Youth Studies. 2018;13(1):72-80. 
15. Byrne T, Montgomery AE, Fargo JD. Unsheltered homelessness among veterans: correlates and profiles. Community mental health journal. 2016;52(2):148-57.

16. Piepoli MF, Hoes AW, Agewall S, Albus C, Brotons C, Catapano AL, et al. 2016 European Guidelines on cardiovascular disease prevention in clinical practice. European Heart Journal. 2016;37(29):2315-81.

17. White BM, Newman SD. Access to primary care services among the homeless: a synthesis of the literature using the equity of access to medical care framework. Journal of primary care \& community health. 2015;6(2):77-87.

18. Broadhead-Fearn D, White KM. The role of self-efficacy in predicting rule-following behaviors in shelters for homeless youth: $A$ test of the theory of planned behavior. The Journal of Social Psychology. 2006;146(3):307-25.

19. Suchting R, Businelle MS, Hwang SW, Padhye NS, Yang Y, Santa Maria DM. Predicting Daily Sheltering Arrangements among Youth Experiencing Homelessness Using Diary Measurements Collected by Ecological Momentary Assessment. International journal of environmental research and public health. 2020;17(18):6873.

20. Arozullah AM, Yarnold PR, Bennett CL, Soltysik RC, Wolf MS, Ferreira RM, et al. Development and validation of a short-form, rapid estimate of adult literacy in medicine. Medical care. 2007:1026-33.

21. Daundasekara SS, Gallardo KR, Maria DS, Hernandez DC, Truong C, Yip M, et al. Shelter Service Utilization among Adults Experiencing Homelessness. Health Behavior and Policy Review. 2019;6(2):128-39.

22. Gonzalez JR, Jetelina KK, Roberts M, Reitzel LR, Kendzor D, Walters S, et al. Criminal justice system involvement among homeless adults. American Journal of Criminal Justice. 2018;43(2):158-66.

23. Vijayaraghavan M, Neisler J, Wrighting Q, Reitzel LR, Hébert ET, Rash CJ, et al. Income associations with cigarette purchasing behaviors and quit attempts among people experiencing homelessness. Addictive behaviors. 2019;95:197-201.

24. TURNHAM J, WILSON E, BURT M. A guide to counting unsheltered homeless people revised. Department of Housing and Urban Development of Community Planning and Development Washington, USA. 2006.

25. Control CfD, Prevention. Behavioral Risk Factor Surveillance System (BRFSS) web site. 2006.

26. Committee DGA. Dietary guidelines for Americans 2015-2020: Government Printing Office; 2015.

27. Control CfD, Prevention. Adult BMI calculator. Division of Nutrition, Physical activity and Obesity. Retrieved from http ...; 2015.

28. Jaffee KD, Liu GC, Canty-Mitchell J, Qi RA, Austin J, Swigonski N. Race, urban community stressors, and behavioral and emotional problems of children with special health care needs. Psychiatric Services. 2005;56(1):63-9.

29. Bickel G, Nord M, Price C, Hamilton W, Cook J. Guide to measuring household food security. Alexandria Department of Agriculture Food and Nutrition Service. 2000.

30. Tsai J, Rosenheck RA. Obesity among chronically homeless adults: is it a problem? Public Health Reports. 2013;128(1):29-36.

31. Martins DC, Gorman KS, Miller RJ, Murphy L, Sor S, Martins JC, et al. Assessment of food intake, obesity, and health risk among the homeless in Rhode Island. Public Health Nursing. 2015;32(5):453-61.

32. Kendzor DE, Allicock M, Businelle MS, Sandon LF, Gabriel KP, Frank SG. Evaluation of a shelter-based diet and physical activity intervention for homeless adults. Journal of Physical Activity and Health. 2017;14(2):88-97.

33. Koh KA, Hoy JS, O'Connell JJ, Montgomery P. The hunger-obesity paradox: obesity in the homeless. Journal of Urban Health. 2012;89(6):952-64.

34. He W, Goodkind D, Kowal P. US Census Bureau, international population reports. An Aging World: 2015. 2016:16-1. 